\title{
Simulation of Amphibious Vehicle Water Resistance Based on FLUENT Xiaochun $\mathrm{Pan}^{1 \mathrm{a}}$, Kai Yao ${ }^{1 \mathrm{a}}$, Ling Duan ${ }^{2 \mathrm{a}}$,Zhongming Hou ${ }^{1 \mathrm{a}}$, ,Xinmin $\operatorname{Tian}^{1 \mathrm{a}}$ and Xiaowen Zhao ${ }^{1 \mathrm{a}}$ \\ ${ }^{1}$ Xi'an Construction Engineering Research Institution, China \\ ${ }^{2}$ Chang'an University, China \\ a987198080@qq.com
}

Keywords: Amphibious vehicles; Water resistance; FLUENT; Resistance simulation

\begin{abstract}
Amphibious vehicle shape changing shape structure, compared with the hull, its water resistance factors more and more computationally complex. Calculated using the traditional theory it is difficult to accurately estimate their water resistance force and distribution. In this paper, the water resistance FLUENT software simulation analysis can more accurately calculate and analyze the water Amphibious Vehicle force distribution. This paper has established amphibious vehicle CFD models, set the environmental parameters and boundary conditions, the amphibious vehicle water resistance characteristics were simulated. Amphibious vehicles obtained two-phase distribution of water vapor, the body and the body surface pressure distribution free surface profile, the final calculation of the amphibious vehicle water resistance values.
\end{abstract}

\section{Introduction}

Amphibious vehicle shape changing shape structure, compared with the hull, its water resistance factors more and more computationally complex. Calculated using the traditional theory is difficult to accurately estimate their water resistance force and distribution, water resistance using FLUENT software simulation analysis can more accurately calculate and analyze the water by the force of the amphibious vehicle distribution, is the current amphibious vehicle exterior design and optimization important methods. Amphibious vehicle can be seen as a special hull, so the amphibious vehicle to simulate water flow field analysis, can learn the basic theory and research methods in ship hydrodynamics research in application of CFD (Computational Fluid Dynamics) technology [1]. Amphibious vehicle and ship motion in the water is very similar, but compared with the viscous flow field around the ship, the amphibious vehicle streamlined worse, higher block coefficient, while the viscous flow around a field around the vehicle will usually separate serious produce large amounts of eddies and the surf, making amphibious vehicle greater numerical hydrodynamic characteristics simulation of difficulty[2-4].

\section{Amphibious vehicles CFD model}

In this paper, the amphibious vehicle is to solve the earthquake, snow, floods, landslides and other natural disasters, roads severely damaged road surface ice, mud, sand accumulation, pits and other bad road conditions, and even the formation of water and land transportation cross under the circumstances, a small obstacle cleared, repair works, personnel recovery, problems transporting supplies.

Complex amphibious vehicle body shape, body protruding structural components more. Therefore, the need for body shape can be simplified to enable it to achieve numerical simulation and emulation. In a simplified model of the process, follow the following principles [5]:

1) Small-scale structure of the vehicle body can be ignored.

2) hydrodynamic performance of the vehicle body accessories and little effect on the structure can be simplified.

3) changes in the surface smoother body part, merge simplified. 
4) For the hydrodynamic characteristics of the vehicle tire, etc. in strict accordance with the larger size model.

5) does not consider the effect of air resistance, the section above the waterline all reduced to flat.

Simplified through the body, the use of three-dimensional modeling software solidworks drawing CAD model, shown in Figure 1.

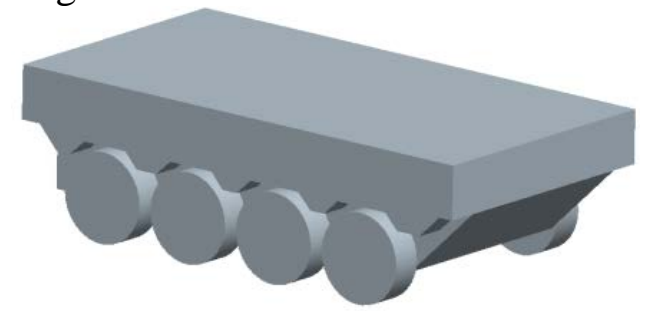

Fig.1 A simplified three-dimensional CAD model amphibious vehicle

Since the body is symmetrical appearance, its numerical simulation in the flow field it is symmetrical, so just take half the actual computing model to model. The body of the three-dimensional CAD model to ACIS files (* sat) in the form of import mesh partition software GAMBIT.

CFD model diagram free surface water and air interface, above the air inlet, here is water inlet. Due to the symmetry of the vehicle body, during modeling time, in order to reduce the number of grids and computing time, select only one side of the vertical plane of the vehicle is calculated, the other side may be obtained by symmetry.

Model uses a three-dimensional Cartesian coordinate system fixed to the water inlet boundary, symmetry intersection boundaries and the bottom boundary of the computational domain origin of coordinates, $\mathrm{x}$-axis direction is negative direction the vehicle is traveling, $\mathrm{y}$-axis perpendicular to the surface upward, z-axis direction to follow the right hand rule, pointing to the side of the vehicle body.

The size of the control region of reference require ships and amphibious vehicles related areas, with limited regional water simulation infinitely broad waters of vehicle movement. The size of the control area is four times the length of the body length, a of 1 times body, body length is 1.25 times higher. Specific dimensions shown in Table 1.

Table 1 Control region size

\begin{tabular}{|l|l|l|l|}
\hline Regional border & Length ( L ) & width (B) & Height (H) \\
\hline Numerical (mm) & 17080 & 4270 & 5337 \\
\hline
\end{tabular}

Model the flow field area is provided with reference to the boundary conditions of FIG. 2, the specific parameter settings as shown in Table 2.

Table 2 Boundary condition parameter setting table

\begin{tabular}{|c|c|c|}
\hline Boundary Name & Setting parameters & Parameter Description \\
\hline Air inlet & VELOCITY_INLET & Speed entrance \\
\hline Water inle & VELOCITY_INLET & Speed entrance \\
\hline Exit & OUTFLOW & Exit \\
\hline Symmetry plane & SYMMETY & Symmetry boundary \\
\hline Body surface & WALL_ & Solid wall boundary \\
\hline Other border & WALL & Solid wall boundary \\
\hline
\end{tabular}

In order to generate a grid file to FLUENT, the model grid output .msh files. 


\section{Amphibious vehicle water resistance simulation parameters}

\section{Setting environment parameters and boundary conditions}

Environmental parameters as shown in Table 3.

Table 3 Environmental parameters

\begin{tabular}{|c|c|c|c|c|}
\hline $\begin{array}{c}\text { Parameter } \\
\text { name }\end{array}$ & $\begin{array}{c}\text { Water Density } \\
\mathrm{kg} / \mathrm{m}^{3} \\
\end{array}$ & $\begin{array}{c}\text { Dynamic viscosity } \\
\mathrm{kg} / \mathrm{m}^{-1} \mathrm{~s}^{-1}\end{array}$ & Air density kg/m³ & $\begin{array}{c}\text { Dynamic viscosity } \\
\mathrm{kg} / \mathrm{m}^{-1} \cdot \mathrm{s}^{-1} \\
\end{array}$ \\
\hline Numerical & 998.2 & 0.001003 & 1.225 & $1.7894 \times 10^{-5}$ \\
\hline $\begin{array}{c}\text { Parameter } \\
\text { name }\end{array}$ & $\begin{array}{c}\text { Environmental } \\
\text { pressure }(\mathrm{Pa})\end{array}$ & $\begin{array}{c}\text { Ambient temperature } \\
\left({ }^{\circ} \mathrm{C}\right)\end{array}$ & $\begin{array}{l}\text { Acceleration of gravity } \\
\left(\mathrm{m} / \mathrm{s}^{2}\right)\end{array}$ & $\begin{array}{c}\text { Operating density } \\
\left(\mathrm{kg} / \mathrm{m}^{3}\right)\end{array}$ \\
\hline Numerical & 101325 & 15 & 9.81 & 1.225 \\
\hline
\end{tabular}

Set the boundary conditions is as follows:

Provided emergency light amphibious rescue vehicle maximum speed in the water $10 \mathrm{~km} / \mathrm{h}$, namely $2.78 \mathrm{~m} / \mathrm{s}$. This article only on the speed under full load state of emergency rescue amphibious vehicle CFD models to simulate.

Air inlet: inlet air to the inlet velocity, the air velocity of $2.78 \mathrm{~m} / \mathrm{s}$, the volume fraction of water is zero.

Water inlet: inlet water inlet velocity is also set, the flow velocity of $2.78 \mathrm{~m} / \mathrm{s}$, the volume fraction of water 1 .

Inlet boundary Dirichlet boundary conditions satisfied: the speed of the entrance to a pre-given, generally uniform incoming flow conditions, turbulent kinetic energy $\mathrm{k}$ and turbulent dissipation rate $\varepsilon$ is also given in advance, will not be corrected and the change in the calculation process must ensure that at this point.

Solid wall boundary: consider the impact of fluid viscosity, the body surface is a solid wall boundary, fluid on the solid wall interface is no relative slip, using wall boundary wall function treatment.

Export: export pressure.

Since the simulation choices are VOF two-phase flow model, the pressure at the outlet pressure value is not constant, but relative pressure above the waterline is 0 relative pressure below the waterline in accordance with the increase of depth $p * g *$ h occurred change (p representative of the density of water, $g$ is the gravitational acceleration, $h$ represents the depth calculation point of water). So you must use FLUENT user-defined function (UDF).

Symmetry boundary: CFD model of the vehicle body in the vertical plane of symmetry boundary where the surface, that is, no fluid through at this interface, the fluid velocity vector and parallel interface.

The default is solid remaining boundary wall boundary.

\section{Initialization and iteration parameters}

Numerical calculations start from the water inlet. Set the initial time of turbulent kinetic energy $0.0289813 \mathrm{~m} 2$ / s2, the turbulent dissipation rate $14.12677 \mathrm{~m} 2 / \mathrm{s} 3$, the flow velocity of $2.78 \mathrm{~m} / \mathrm{s}$, CFD model for the entire flow range area below the waterline in the area,shown in Figure 3, blue area is the location of the initial time of water, red for empty.

Before the iterative calculation, the residual convergence criteria set 0.00001 ; set the timestep is 0.001 , total number of steps of 2000, the maximum number of iterations per time step is 10 . After 30 hours of continuous work computer to obtain a converged solution. 


\section{Resistance Simulation and Analysis of Results}

\section{Vehicle moisture distributions and Analysis}

Figures 2 and 3 are two-phase distribution of the body of the head and tail. As can be seen from the figure, the vehicle has swept over the head of water above the water line, and in the side and rear of the vehicle body below the surface, but below the waterline. Since the plane of the front retaining effect, so that the water in this together, up above the waterline. Retaining the same time as the head of the body shape changes and rapid, sudden drops of water on both sides of the body below the surface waterline. In particular the rear body, after water flows through the vehicle side, sudden change in shape due rear, water late aggregation, so the waterline in this violent depression.

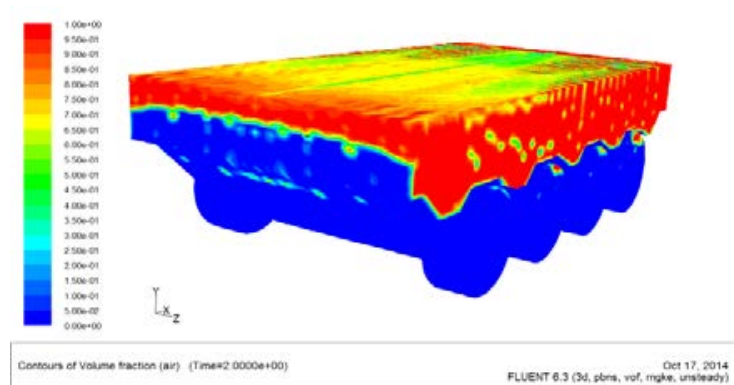

Fig.2 Moisture profile of the body surface

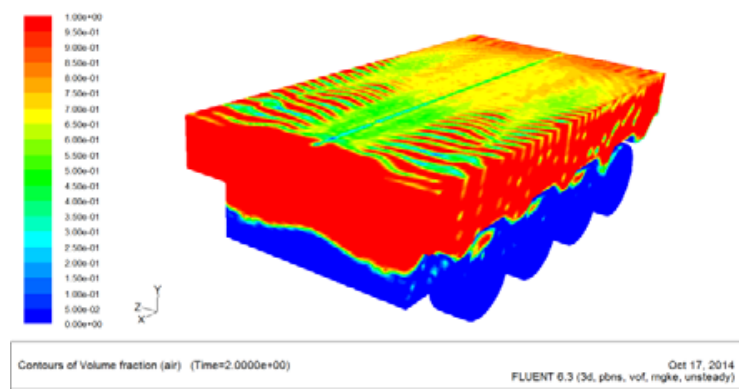

Fig.3 Body surface moisture distribution

\section{Body surface pressure distribution and analysis}

Figures 4 and 5 respectively, the body of the head and tail of pressure contours. As can be seen from the figure, the front wheel side is formed at the bottom of the high pressure zone four, partly because the water depth is relatively large, high hydrostatic pressure, on the other hand is caused by the relative motion of the water, we can see that, since the wheels projecting structure, the amphibious vehicle water resistance increased significantly. Especially the front wheel of the first pair, the pressure reaches the maximum, mainly affected by the front part of the water that has accumulated. Overall pressure than the larger body of the head. While the first pair of wheels side, forming a low pressure area and negative area, the front of drastic change, clogging occurs in front of the water. Before the positive side of the vehicle body at the bottom of the transition zone, the formation of a negative pressure zone, water and body separation occurs, it proved a poor front of the shunt effect. In the rear part, due to the flow depression, pressure is very small, thus forming a front and rear body section pressure drag (shape resistance), special amphiphobic body structure, so the pressure drag of the vehicle is very large, especially when the vehicle speed increases, the pressure resistance will rapidly increase.

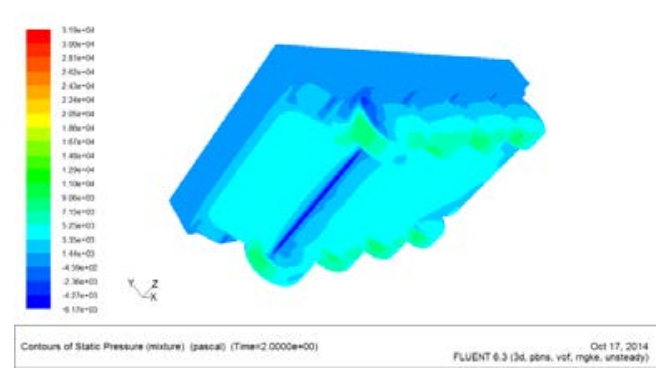

Fig.4 Body pressure cloud

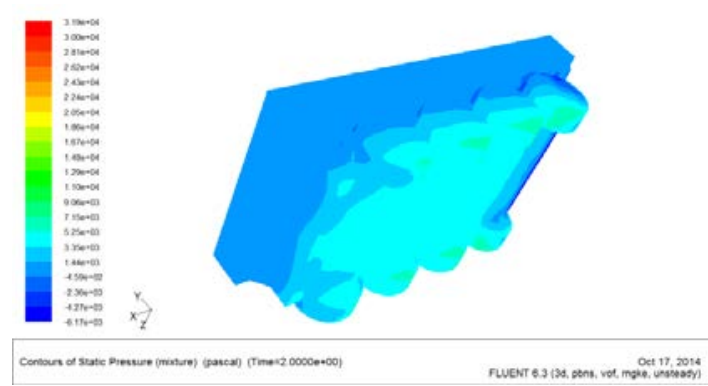

Fig.5 Body contours pressure 


\section{Analysis of the Distribution of free surface body}

Figure 6 maps for the free surface. As can be seen from the figure, the vehicle front and rear body formed a large wave. Especially the front part of the body of water in front heap plug, forming a "wall of water", while forming wave crest in the front office, in the rear part of the wave trough is formed, resulting wave making resistance. Analysis of the figure shows that the waves around the body, the square in front of the vehicle body front side, blocking the diversion to flow, thereby forming a crest in front of the car and spread forward vehicle voyage; rear body due to relatively square rear poor diversion effect, so that the water in this depression, forming a trough, during the voyage, the flow to the rear of the gathering. Studies have shown that wave making resistance with the speed of increase will increase dramatically, it is necessary to optimize the shape of the body is water in the front and rear can transition smoothly, thereby reducing the wave making resistance.

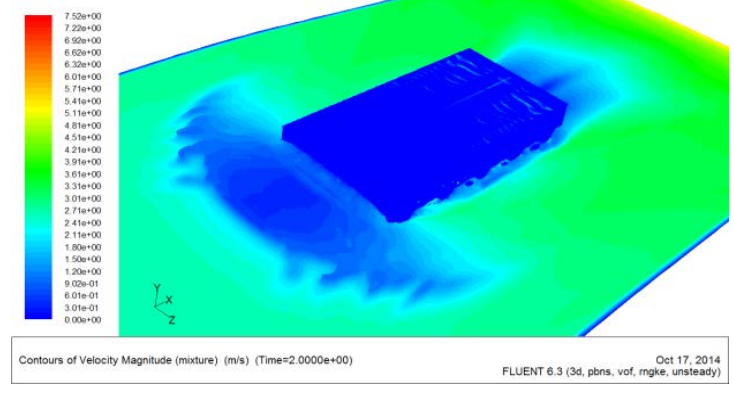

Fig.6 Body free surface profile

\section{Conclusion}

Aiming amphibious vehicle shape changing shape structure, calculated using the traditional theoretical problem which is difficult to accurately estimate the water resistance of the force and distribution. Water resistance using FLUENT software simulation analysis, the amphibious vehicle CFD models, set the environmental parameters and boundary conditions, the amphibious vehicle water resistance characteristics were simulated. Amphibious vehicles obtained two-phase distribution of water vapor, the body and the body surface pressure distribution free surface profile, more accurate simulation of the amphibious vehicle and water resistance force distribution.

\section{References}

[1] Miao Q M,Chwang A TThe effect of submerged vertical walls on ship waves[A].The 14th Engineering Mechanics Conference[C],EM2000(CD-Rom),Austin,Texas,USA,2000.

[2] Miyata H,Kanai A.Numerical analysis of structure of free-surface shock wave about a wedge model[J].Journal of Ship Research,Dec.1996,40(4):278-287.

[3] Stern F,Paterson E C,Tahara Y.CFDSHIP-IOWA:Computational Fluid Dynamics Method for Surface-ship Boundary Layers,Wake and Wave Fields[R].IIHR Report No.3 8 1,Iowa Institute of Hydraulic Research,Iowa,July,l 996.

[4 ]ZHANG Zhi-rong,ZHAO feng,LI Bai-qi.Numerical calculateions of viscous free-surface flow about ship hull[J].J.of Ship Mechanics.2002,6(6):10-17.

[5] GAO Qiu-xin,SHU Lei.Numerical simulation of free surface flow around frigate model 5415[J].J.of Ship Mechanics.2002,6(6):1-9. 